\begin{tabular}{|c|c|c|}
\hline $\begin{array}{l}\text { PKS } \\
\text { PUBLIC } \\
\text { KNOWLDEE } \\
\text { PROJECT }\end{array}$ & $\begin{array}{c}\text { Revista de GEOGRAFIA } \\
\text { (RECIFE) } \\
\text { nttp://www.revista.uffe.br/revistageografia }\end{array}$ & $\begin{array}{l}\text { OJS } \\
\frac{\text { OPEN }}{\text { OPENAL }} \\
\text { SYSTEMS }\end{array}$ \\
\hline
\end{tabular}

\title{
MEDOS E MUROS EM CASA FORTE: TOPOFOBIAS DO RECIFE
}

\author{
Lourival Luiz dos Santos Junior ${ }^{1}$, Bruno Maia Halley ${ }^{2}$ \\ ${ }^{1}$ Mestrando em Geografia na Universidade Federal de Pernambuco. Email: santosgeoll@yahoo.com.br \\ ${ }^{2}$ Pós-doutorando em Geografia na Universidade Federal de Pernambuco.Email: bhalleype@gmail.com
}

Artigo recebido em 04/09/2017 e aceito em 01/10/2017

\begin{abstract}
RESUMO
O medo generaliza-se no imaginário e na forma urbana, reproduzindo um quadro de insegurança coletiva, com as "casas fortes" se multiplicando pela cidade. No Recife, o emanar de "edifícios-claustros", ruas privatizadas, mansões e condomínios fechados, tecnicamente fortificados por guaritas, muros altos, cercas, espelhos e câmeras de vigilância, parece associar-se com espaços analogicamente opostos, estigmatizados como lugares do medo/insegurança. São recortes topofóbicos da cidade materializados em ruas escuras, becos, terrenos baldios, casas abandonadas, morros e comunidades pobres existentes à beira de rios. Situado na Zona Norte do Recife, o bairro de Casa Forte externa em sua paisagem e no sentimento dos seus moradores mais abastados essa realidade paradoxal, com muros materiais e imateriais erguidos à todo momento, intensificando estigmas, medos e estranhamentos. As dimensões concretas e simbólicas desta geografia do medo serão esmiuçadas, tomando como análise os temores e claustros de Casa Forte, aqui apreendido como um "bairrofobia".
\end{abstract}

Palavras-chaves: Medo. Bairro. Topofobia. Casa Forte. Recife.

\section{FEARS AND WALLS IN CASA FORTE: RECIFE TOPOPHOBIAS}

\begin{abstract}
Fear generalizes in the imaginary and in the urban form, reproducing a context of collective insecurity, with the "strong houses" multiplying by the city. In Recife, the emanation of "cloistered-buildings", privatized streets, mansions and gated community, technically fortified by guaritas, high walls, fences, mirrors and surveillance cameras, seems to associate with analogically opposite spaces, stigmatized as places of fear /insecurity. They are topiphobic cuts of the city materialized in dark streets, alleys, vacant lots, abandoned houses, hills and poor communities on the riverside. Located in the North Zone of Recife, the neighborhood of Casa Forte, outside in its landscape and in the feeling of its wealthiest residents this paradoxical reality, with material and immaterial walls erected at all times, intensifying stigmas, fears and strangeness. The concrete and symbolic dimensions of this geography of fear will be analyzed, taking as analysis the fears and cloisters of Casa Forte, here apprehended as a "phobia-neighborhood".
\end{abstract}

Keywords: Fear. Neighborhood. Topphobia. Casa Forte. Recife. 


\section{CONSIDERAÇÕES INICIAIS}

O sentimento de medo generaliza-se no imaginário e na forma urbana, reproduzindo um quadro de insegurança coletiva na cidade. Dificilmente encontrar-se-á alguém que escape à essa realidade. Fatores inerentes à existência humana no tocante à insegurança misturam-se aos infinitos temores da imaginação, delimitando "topofobias" (TUAN, 2005). As cidades brasileiras intensamente segmentadas, desiguais, convivem com a banalização da violência, das redes do tráfico de drogas, dos crescentes homicídios, furtos e roubos, aos inconvenientes com vizinhos, parentes e desconhecidos, seja em casa, no trânsito e nos locais de trabalho e consumo, seja nos lugares que deveriam ser de divertimento e lazer. Neste quadro, memórias e experiências cotidianas vão desenhando uma realidade material e simbólica do medo, com a naturalização de reclusões, negações públicas e enclausuramentos.

As "casas fortes" se multiplicam pelas cidades "resguardando" os medos dispersos das pessoas e famílias. No Recife, o emanar destes objetos (“edifícios-claustros”, ruas privatizadas, mansões, condomínios fechados, shopping-centers...), tecnicamente fortificados por aparatos de segurança (guaritas, muros altos, cercas, espelhos, câmeras de vigilância...), parece associar-se com espaços analogicamente opostos, estigmatizados como lugares do medo/insegurança - recortes topofóbicos da cidade. Lado a lado aos claustros urbanos, uma geografia de ruas escuras, becos, terrenos baldios, casas abandonadas, morros e comunidades pobres existentes à beira de rios, perfazem o espaço recifense, construindo também um imaginário do medo associado aos "contra-usos" praticados em tais lugares, expressos inclusive no vocabulário popular dos citadinos. São "toponímias do medo", vernáculos de geografias marginais, transmitidos por um sentimento real e imaginário: "beco da fuga", "caminho do estupro", "rua do assalto", "da zuada", "boca de fumo"... Outras toponímias oficiais também recordam esse medo e violência, como Linha do Tiro, Alto do Refúgio, Aflitos e Afogados, que malgrado suas distintas memórias e experiências, ainda assim explicitam os temores vividos na capital pernambucana.

Situado na Zona Norte do Recife, o bairro de Casa Forte externa em sua paisagem e no sentimento dos seus moradores essa realidade paradoxal. Desde sua ocupação inicial no século XVII, como reduto senhorial do açúcar, das terras de engenhos às margens do rio Capibaribe, o bairro singulariza-se como um recanto de classes privilegiadas de Pernambuco. $\mathrm{Na}$ ordem do dia, repleto de atrativos urbanos e amenidades naturais, o lugar encontra-se imerso em construções históricas, casas comerciais e de serviços, praças e jardins 
monumentais, além dos seus vários "edifícios-claustros", moradias da atual elite econômica do bairro. Em contraste, evidencia-se no entorno, outras ocupações marcadas por residências de autoconstrução, tanto no sentido dos morros e ladeiras do bairro vizinho de Casa Amarela, como nas margens baixas do Capibaribe, nas comunidades pobres do Monteiro e Santa Luzia. Neste desarranjo espacial, muros materiais e imateriais são erguidos, intensificando medos e estranhamentos, sobretudo na temporalidade noturna, mais propícia para construção de topofobias entre os citadinos.

As dimensões concretas e simbólicas desta geografia do medo serão esmiuçadas no trabalho ora apresentado, tomando como análise os temores e claustros de Casa Forte, aqui apreendido como um "bairrofobia", em contraposição à ideia de "bairrofilia" preconizada por Souza (1988) ao tratar do apego e afetividade das pessoas ao seu bairro de vivência. De um sentimento topofilico, de afeição, harmonia e apego ao lugar, procurou-se retratar sensações topofóbicas, do caos, do desamparo, e da insegurança em Casa Forte. Adotou-se a perspectiva dos moradores do entorno da Praça de Casa Forte, os seus medos em residir no bairro, embora o temor também esteja presente entre os mais populares do lugar, ameaçados constantemente pela polícia, traficantes e assaltantes, afora outras formas de violência associadas à miséria e ao descaso público presentes entre aqueles que moram à beira de córregos e nos mangues do Capibaribe. Mesmo desfavorecidos, a vida explode nos endereços dos mais pobres do bairro, em contraposição aos espaços dos mais ricos, confinados em seus receios e estigmas sociais, características de um modelo de comportamento que nega a existência do "outro".

\section{DE CONDIÇÃO HUMANA À CONDIÇÃO GEOGRÁFICA: EXPERIÊNCIAS DO MEDO NO RECIFE}

Sentir medo trata-se de uma condição da existência humana, companhia constante nos diversos espaços-tempos da história. $\mathrm{Na}$ trajetória da humanidade, medos distintos foram eleitos, reais ou imaginários, desde aberrações, lugares sinistros, temores circunstanciais, até pessoas e grupos de origem distintas e fenômenos da natureza. Todos estes casos construíram insegurança. As intempéries naturais conduziram o homem a construir refúgios, recolher-se em cavernas e grutas para abrigar-se das chuvas, raios e de animais ameaçadores. Ao mesmo tempo negava-se florestas densas e fechadas por serem locais de amedrontamento, lendas e fábulas diversas da imaginação. São vários os exemplos sobre medo e insegurança na história humana, também alimentados por "forças ocultas”, não visíveis e não audíveis, no seio de um mundo real (CLAVAL, 2010). 
$\mathrm{Na}$ condição de maior expressão material humana, a cidade se apresenta como um rico laboratório para se refletir sobre o medo e insegurança na ordem do dia. Devido as diversas formas de violência reproduzidas, o medo urbano disseminou-se na totalidade, alargando o sentimento de insegurança, de risco iminente, pelo imaginário dos citadinos. A propósito, Mia Couto, em conferência sobre segurança, chegou a afirmar que "há quem tenha medo que o medo acabe". ${ }^{2}$ Em qualquer situação não há como escapar deste contexto. Os fenômenos mesmo que sejam produzidos, a princípio, imaterialmente, em algum momento materializamse (GONÇALVES, 2002). Com efeito, o medo possui uma condição geográfica. A geografia nunca deve ser pensada somente numa dimensão material, pois a realidade físico-concreta se imbrica continuamente à dimensão simbólica. Neste sentido, a insegurança torna-se factível no imaginário e no espaço. O clima de insegurança das cidades engendra a multiplicação de inúmeras topofobias, multiplicando-se também os interesses na proliferação deste medo, calcados na produção e comercialização de artefatos de segurança, materialmente expressos nos espaços da cidade.

A insegurança urbana contribui para fomentar estratégias de "proteção", vivenciadas em ações e precauções cotidianas, contornos pensados para sobreviver sem maiores traumas na cidade. Uma transeunte de Casa Forte, imersa em suas reminiscências, registrou a ousadia dos assaltantes no bairro: "você pode guardar até no cérebro, mas eles irão buscar seu relógio, seu celular". ${ }^{2}$ Em face essa truculência, o corpo humano enquanto primeiro território, se torna vulnerável, engendrando a recriação de inúmeras estratégias por parte dos citadinos. Com cautela utiliza-se o aparelho de telefonia móvel pelas ruas. Em alguns casos, adquire-se dois aparelhos, caso ocorra um assalto, entrega-se apenas um de menor valor. Também oferece-se outros objetos (relógio, pulseiras, colares, dinheiro...), como forma de evitar maior violência. Costumeiramente evita-se transitar com os vidros abaixados do automóvel, como também aconselha-se não permanecer em espaços públicos em determinados horários, sobretudo no período noturno. São práticas corriqueiras, quase naturalizadas na cidade, em tempos de medo e pavor exacerbado.

No imaginário urbano, espaços ermos são apreendidos como perigosos, engendrando a recriação de "toponímias do medo". Conforme ressaltado, no Recife, a vox populis evoca cotidianamente geografias temidas, como "caminho do estupro", "do assalto", "boca de

\footnotetext{
${ }^{1}$ COUTO, M. "Murar o Medo". In: Conferência de Estoril, 4, 5 e 6 de maio, Portugal, 2011. Disponível em: www.estorilconferences.org/pt. Acesso: 15 de maio de 2017.

${ }^{2}$ Adriana Galdino, 22 anos, empregada doméstica no bairro de Casa Forte, em depoimento colhido em 16 de junho de 2017. 
fumo", "beco da morte", entre outras expressões. Tratam-se de "vernáculos topofóbicos", cultuados pelos indivíduos, sobretudo nos bairros e comunidades pobres, como também nos diversos meios de informação (jornais, programas de rádio e TV). À todo instante disseminase o medo, estimulando, entre outros aspectos, a indústria de segurança, e, por conseguinte, a construção de claustros nos bairros de média e alta renda da cidade. As contenções físicoterritoriais são recriadas em diversos espaços, recriando-se também “muros simbólicos" entre as classes socioeconômicas do Recife.

Estudos mais recentes ressaltam o papel desempenhado pelos meios de informação na reprodução do medo, intensificando paradoxos territoriais na cidade a partir do discurso da insegurança. No dizer de Cruz (2010), quando a mídia "vende o medo", circulando-o através da informação, as pessoas acabam "comprando segurança". O medo é, assim, manipulado pelos grupos hegemônicos, instrumentalizado para devidos fins (Id., Ibid.). Caldeira (2011), por sua vez, ressalta a fala do crime como um discurso contagiante, circulando sensações de perigo, insegurança e perturbação entre as pessoas. Fatores políticos, econômicos e espaciais enfatizam a reprodução do crime, do medo e do estigma na cidade. Caldeira menciona o preconceito contra a ocupação de nordestinos no bairro da Mooca em São Paulo. A partir da fixação de um grupo social distinto, o bairro acabara se tornando num local "desinteressante", e até mesmo “desagradável' para os antigos moradores, os quais relacionaram o aumento da criminalidade, e a consequente decadência do lugar, à chegada dos nordestinos (Id., Ibid.).

É evidente que o medo cumpre um papel diário, não apenas como um alerta constante da condição humana, mas também como resultado da diluição moral e ética da sociedade, aguçando preconceitos contra as camadas mais pobres. O medo materializa-se em aparatos de segurança, ganhando formas distintas no controle da população, com os agentes hegemônicos e o Estado agindo, muitas vezes, de forma violenta contra os mais despossuídos da cidade. As várias "casas fortes" abrigam os distintos medos dos mais afortunados, os quais encontram-se aprisionados em preconceitos, intensificando mais fechamentos espaciais. O mundo da casa, do trabalho, do lazer e consumo engendra isolamentos e individualidades, consolidando relações sociais mais frias e anônimas, dentro de um cenário intra-muros, construído como abrigo contra um temido encontro com o "outro". Evita-se o perigo e a imprevisibilidade do acaso, suscitando mais separações no contexto já bastante segregado das cidades brasileiras, historicamente fragmentadas em seus territórios.

Em face essa realidade, múltiplos muros são erguidos, configurando desde contenções físico-territoriais às paredes simbólico-culturais. Os limites do preconceito e da insegurança 
são cada vez mais visíveis e vividos pelos diferentes sujeitos. Spósito (2013), Caldeira (2011), Sá $(2009)^{3}$ e Souza (2008) se propuseram analisar os atuais processos de "fechamento" das cidades no tocante à crescente negação da rua, do público, por segmentos da sociedade trancafiados em seus autolimites. Não se nega apenas determinados espaços, nega-se a vida em suas distintas temporalidades, contrariando o princípio da existência na ótica de Arendt (2011), segundo o qual viver é estar entre os homens, entre seus semelhantes na totalidade, e não apenas entre os semelhantes de poder, status e enclausuramento. Contudo, ao que parece na realidade, a riqueza, o poder e os recursos estão se tornando mais concentrados nas mãos dos poderosos, isolados em casulos urbanos murados, onde se implantam sistemas de segurança ou forças paramilitares, para a tarefa de imposições, vigilâncias e controle de acesso (GRAHAM, 2016).

O mundo das "muralhas" contrapõe-se ao mundo da "virada espacial", da fluidez em curso, da liberdade dos corpos e da expressão de intersubjetividades. A propaganda de uma empresa de telefonia explícita a atual retórica da liberdade em tempos de globalização: "viver sem fronteiras". Mas será mesmo que vivemos sem limites? Malgrado os discursos, cada vez mais materializam-se muros nas fronteiras de regiões, nações e cidades. Embora vivencie-se o período popular da história, marcado por uma fluidez técnica e informacional, intensificam-se desigualdades, valores contrários, medos e individualismos dentro de um multiculturalismo global. No mundo há "um sistema de objetos "perfeitos" técnicos, científicos e informacionais agregador nas suas funcionalidades, mas desagregador nas suas sociabilidades” (SÁ, 2009, p. 7-8). Em seus aparatos, o medo ordena o mundo, e ao mesmo tempo, desagrega o território.

$\mathrm{Na}$ condição de retórica, utiliza-se a insegurança para instrumentalizar meios técnicos, especialmente nos espaços urbanos. A eleição pelas classes privilegiadas de possíveis "perigos humanos", como o "favelado", o "morador de rua", o "negro", ou as "classes populares", e de "topofobias urbanas", como "becos", "ruas escuras", "casas abandonadas", e "comunidades pobres", difunde-se cotidianamente pelo imaginário dos citadinos, tornando o espaço de ruas e bairros cada vez mais denso em parafernálias de segurança. Em meio às ruas privatizadas, condomínios fechados e "edifícios-claustros", homens fardados, guaritas, arames farpados, câmeras de vigilância e cercas elétricas, desenham os quarteirões, sobressaindo a imagem dos

\footnotetext{
${ }^{3}$ Como um dos precursores no estudo das Geografias da Violência e do Medo no Brasil, o geógrafo e economista Alcindo José de Sá vem desenvolvendo investigações a esse propósito há mais de uma década, sobressaindo as seguintes publicações: Sá \& Cruz (2011) e Sá (2012). Além destes escritos, Sá orientou dezenas de estudos no Programa de Pós-Graduação em Geografia da Universidade Federal de Pernambuco, destacandose os trabalhos de mestrado e doutorado de Luciana Maria da Cruz (2010; 2015), sobre a materialização da (in)segurança em bairros nobres do Recife, inclusive em Casa Forte. 
muros altos nas cidades, como no Recife, murada em cimento, tijolos e corpos aprisionados. Parafraseando Mia Couto, “esses corpos convertidos em muro e pedra são uma metáfora do quanto o medo nos pode aprisionar". Ademais, "há muros que separam nações, há muros que dividem pobres e ricos, mas não há hoje, no mundo um muro, que separe os que têm medo dos que não têm medo. Sob as mesmas nuvens cinzentas vivemos todos nós, do sul e do norte, do ocidente e do oriente" (COUTO, 2011).

A sombra do medo encobre a cidade. Os muros nas suas ruas ditam a impessoalidade. Transformam-se em locais de passagem desprovidos de apropriações concretas e vividas. As barreiras evidenciam o desejo pelo privado, em detrimento ao público, ao encontro de outros moradores da mesma rua, quarteirão ou bairro. Tornam-se lugares de insegurança, em razão dos traumas e da violência presente, os quais engendram "marcas traumáticas" na paisagem, visíveis nas linhas de elevação dos muros residenciais (Figura 01). O testemunho destas marcas junto com a presença constante de aparatos de segurança evidencia as sensações de medo em se residir na cidade, sobretudo no tocante aos "emparedados" do Recife, em especial do bairro de Casa Forte, caracterizado por uma geografia topofóbica semiografada às margens do rio Capibaribe.

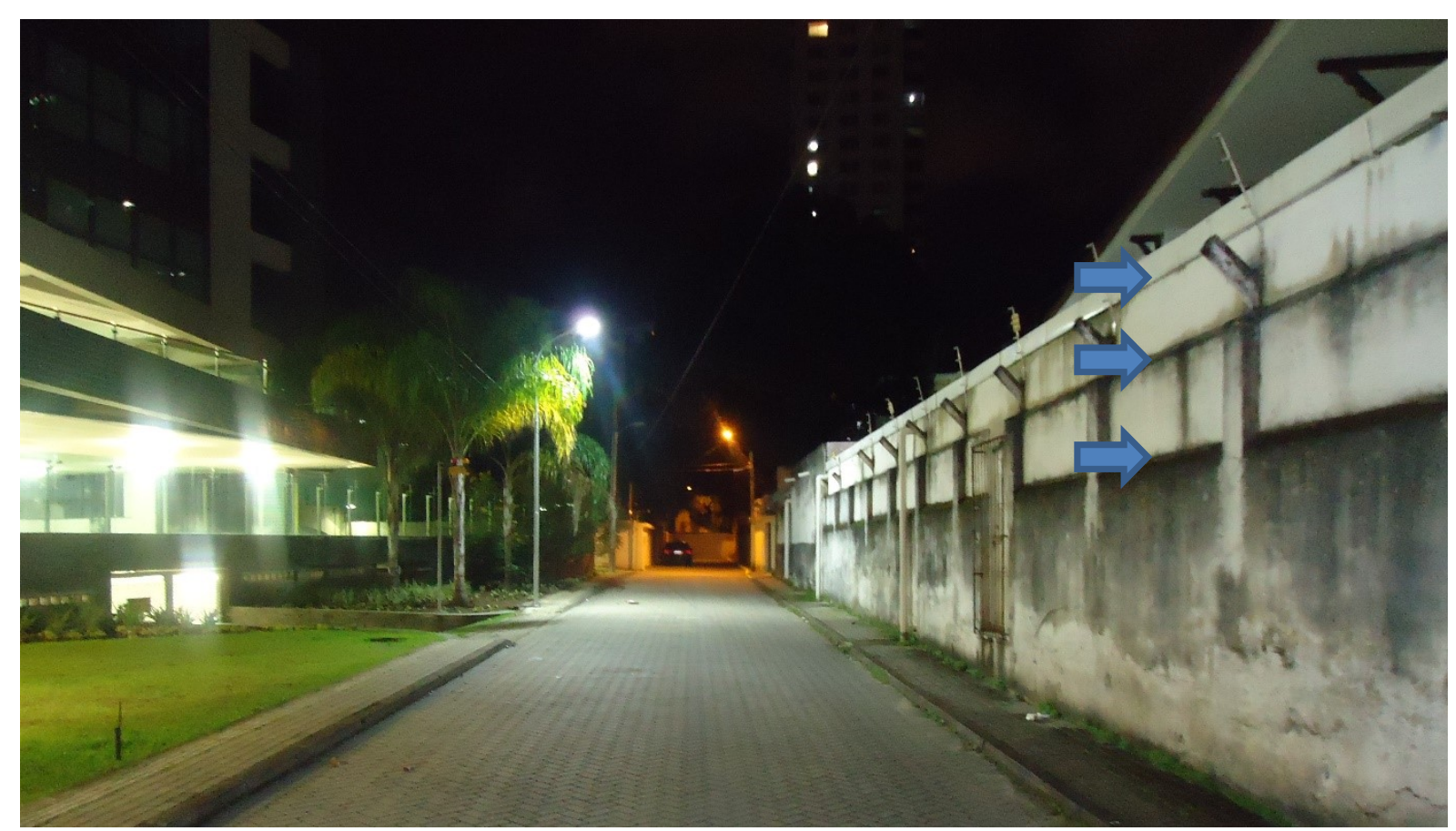

Figura 01: "Marcas traumáticas" no Beco do Cardim, bairro de Casa Forte, visíveis nos níveis de elevação do muro residencial à direita, conforme indicados nas setas da imagem.

Fonte: Acervo de Bruno Maia Halley, junho de 2017. 


\section{MEDOS, MUROS E CLAUSTROS: O BAIRRO DE CASA FORTE E SUA GEOGRAFIA TOPOFÓBICA}

Situado na Zona Norte do Recife, o bairro de Casa Forte tem sua identidade associada aos grupos hegemônicos-tradicionais desde os tempos mais pretéritos, do antigo engenho açucareiro do século XVI, passando pelo concorrido arrabalde no século XIX ao atual bairro. As memórias elitistas do bairro encontram-se reproduzidas constantemente nas fachadas de edifícios residenciais, nas casas de comércio e serviço, e nas praças monumentais: edifícios Senzala, Casa Grande de Sant'anna, Sobrado Gilberto Freyre, entre outros. Difunde-se a imagem do bairro como um local privilegiado, meandrado pelo rio Capibaribe, refúgio de amenidades naturais e de uma infraestrutura urbana singular. A Praça de Casa Forte (Figura 02) conforma-se no "coração simbólico do bairro" (HALLEY, 2014), concentrando diferentes especificidades materiais e imateriais no seu entorno (as árvores, os prédios, a praça, as lojas comerciais...), as quais podem ser aprendidas como "geossímbolos", compreendidos como "um lugar, um itinerário, uma extensão que, por razões religiosas, políticas ou culturais, aos olhos de certas pessoas e grupos étnicos assume uma dimensão simbólica que fortalece sua identidade" (BONNEMAISON, 2002, p. 109).

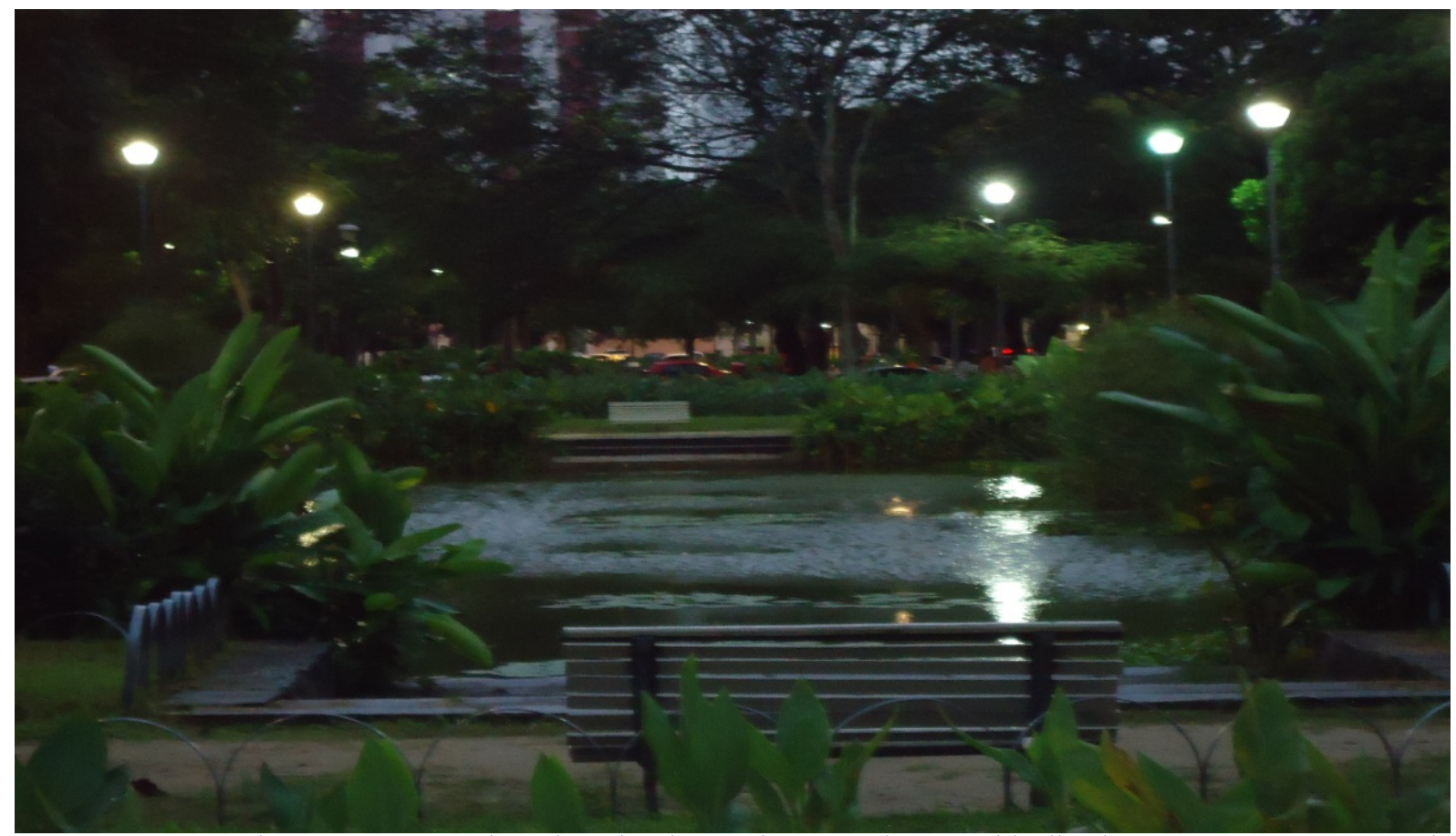

Figura 02: Praça de Casa Forte, projeto do paisagista Roberto Burle Marx idealizado em 1937. No entorno do "coração simbólico do bairro" há vários "edifícios-claustros", com 20-30 andares de altura.

Fonte: Acervo de Lourival Luiz dos Santos Junior, junho de 2017. 
Não obstante a existência dos "geossímbolos" da aristocracia do bairro - a praça, os "edifícios-claustros", a Paróquia de Casa Forte, o rio Capibaribe, os condomínios fechados, entre outros, a espessura do bairro revela-se permeada por outros espaços que remetem ao medo, tratando-se de recortes topofóbicos. Ao se distanciar do "coração do bairro" e de seus "edifícios-claustros" circundantes, emana na paisagem, aqui e acolá, terrenos baldios, casas abandonadas, espaços ermos, becos e ruas sem saída, até alcançar às áreas limítrofes do lugar circunscritas às margens do Capibaribe, ao Sul, e no sopé das colinas, ao Norte. O antigo reduto senhorial do Recife encontra-se circundado por comunidades pobres, as quais acabam por intensificar o sentimento de insegurança por parte da atual elite econômica do bairro refugiada em seus claustros residenciais e nos seus automóveis cada vez maiores e mais escuros, lembrando "carros-fortes" com mínima visibilidade interna. Dentro e fora de seus edifícios, a vida elitista do bairro conforma-se numa individualidade exacerbada, atestando um "novo urbanismo" (CARLOS, 1996) calcado no estranhamento e negação à vida coletiva, aos distintos modelos de comportamento vivenciados na cidade.

A eleição de topofobias reais e imaginárias por esse perfil de moradores de Casa Forte intensifica a imagem dos espaços públicos do bairro como endereços do medo, do perigo, do alerta... Na ótica de Yi-Fu Tuan, o medo configura um "[...] sentimento complexo, no qual se distinguem [...] dois componentes: sinal de alerta é detonado por um evento inesperado e imperativo no meio ambiente. Por outro lado, a ansiedade é uma sensação difusa de medo e pressupõe uma habilidade de antecipação" (TUAN, 2005, p. 10). O alerta e a antecipação promovida pela ansiedade das quais trata Tuan fora observada numa visita à Casa Forte no período noturno (por volta das 19:00h). Nesta incursão ao bairro avistara-se o "Beco da B" no final da Rua Edson Álvares (Figura 03), espremido pelo muro do CPOR, em toda extensão guarnecido por arames farpados ${ }^{4}$, e pelo muro do Edifício Cristalle, protegido por cerca e portão elétrico, com placa fixada com a seguinte mensagem: “A noite: ao se aproximar do portão, ascender luz interna, baixar o farol e vidro (do automóvel)". Já no estreito corredor, uma mulher se aproximou evidenciando nas suas reações corpóreas a sensação de alerta e de antecipação ao possível "perigo" frente à nossa presença no beco. Seu andar rápido, o olhar para baixo, e as mãos firmes a segurar a bolsa de colo denunciaram o medo em transitar por aquele recorte topofóbico de Casa Forte, sobretudo durante à noite. ${ }^{5}$

\footnotetext{
${ }^{4}$ Trata-se do "muro de fundo" do Centro de Preparação de Oficiais da Reserva - CPOR - Exército Brasileiro, com entrada principal na Avenida 17 de agosto, no bairro de Casa Forte.

${ }^{5}$ A propósito do imaginário estigmatizado do "beco" na cidade do Recife enquanto espaço noturno, do medo, da insegurança, e do descaso público, paradoxalmente às suas evocações populares permeadas por um sentimento Santos Junior, Halley 2018 ISSN 0104-5490 244
} 
Paradoxalmente, também observara-se in loco que o medo constrói no bairro uma rede de relações, envolvendo as pessoas no compartilhamento de experiências negativas: memórias sobre assaltos, furtos, invasões à domicílios, entre outros. Foram vários os relatos coletados entre moradores e trabalhadores do bairro, chamando atenção para os casos dos "motoqueiros", os quais utilizam a motocicleta como meio para suas investidas e fugas. O próprio capacete esconde a face do infrator, causando certo temor aos transeuntes do bairro, e da cidade em si, quando avistam algum motociclista, meliante ou não. Nas circunvizinhanças de Casa Forte há um fluxo constante destes condutores, sobretudo nas fronteiras do bairro, no encontro com o Capibaribe, no seu limite meridional. Na margem esquerda do rio, já nas imediações do bairro vizinho de Santana, há uma ponte de pedestre (Figura 04) conectando o lugar à comunidade de Santa Luzia (bairro da Torre), na margem direita (Figura 05). Também foram vários os relatos de fuga pela travessia, ora de "motoqueiros", ora de assaltantes a pé, que realizaram seus crimes nos bairros de Santana e Casa Forte fugindo pela ponte rumo à outra margem do Capibaribe. Além de caminho de fuga, a própria ponte serve de espaço para criminalidade. Recentemente houve um assalto nesta travessia, ganhando ressonância nos meios jornalísticos. Um grupo de estudantes foi surpreendido com a ação de meliantes armados com facões. Tiveram carteiras, bolsas e aparelhos celulares roubados, com os criminosos evadidos para dentro da comunidade de Santa Luzia. ${ }^{6}$ Em outros casos, conforme depoimentos colhidos, as fugas de assaltantes ocorreram à nado pelo rio ${ }^{7}$, em meio aos mangues, ousadias já recorrentes nos bairros centrais do Recife e até mesmo em lugares mais distantes da cidade. ${ }^{8}$

de pertencimento entre os citadinos, vide: HALLEY, B. M. Arruando pelo beco: um nome do passado evocado no afeto e no desamor da gente da cidade. Revista de Geografia, PPGEO (UFJF), v. 2, n 1, 2012.

6 "Alunos são assaltados e jovem é ferida em aula extraclasse no Recife". [...]. Um grupo de estudantes da Universidade Católica de Pernambuco (Unicap) foi assaltado no final da manhã desta segunda-feira (21) na comunidade de Santa Luzia, Zona Norte do Recife. Cerca de 25 alunos do $5^{\circ}$ período estavam realizando uma atividade para o curso de Arquitetura e Urbanismo, durante o horário da aula, quando pelo menos cinco suspeitos armados com facões chegaram ameaçando o grupo. Uma das jovens ficou ferida durante o tumulto. De acordo com uma das estudantes, o grupo estava em uma ponte saindo da Vila Santa Luzia em direção ao Parque Santana, quando foi abordado". Vide: http://jconline.ne10.uol.com.br/canal/cidades/policia/noticia/2017/08/ 21/alunos-sao-assaltados-e-jovem-e-ferida-em-aula-extraclasse-no-recife-302455.php. Acesso: 22/09/2017.

${ }^{7}$ De acordo com o vigilante de rua em Casa Forte, Fábio Silva, 28 anos: "o tempo todo tem alguém aprontando por aqui! Eu já sei por onde eles vão... Depois que roubam vão sempre em direção ao mangue, à maré do rio! $\mathrm{E}$ eu vou atrás!". Em depoimento colhido em 25 de maio de 2017.

${ }^{8}$ Vide a matéria jornalística de 07 de julho de 2017: "Homem pula de ponte para fugir pelo rio durante perseguição policial no Recife - Ele tentou fugir pelo Rio Capibaribe, mas foi preso pela PM, que também prendeu outro suspeito. Quatro homens estavam dentro de carro roubado e dois conseguiram fugir". Disponível em: https://g1.globo.com/pernambuco/noticia/homem-pulade-ponte-para-fugir-da-policia-durante-perseguicao-policial-no-recife.ghtml. Acesso: 02/10/2017. Vide também a matéria de 23 de janeiro de 2017: "Homem tenta fugir pelo Rio Capibaribe após assalto no Recife". Disponível em: http://radiojornal.ne10.uol.com.br/noticia/2017/01/23/homem-tenta-fugir-pelo-rio-capibaribe-apos-assaltono-recife-52028. Acesso: 02/10/2017. 
Em várias áreas do Recife, o Capibaribe se apresenta como um "muro líquido". Separa realidades sociais distintas na cidade, ao mesmo tempo que reforça diferenças e estigmas. No caso abordado, a travessia sobre o rio conecta bairros de médio e alto padrão de renda, antigos redutos senhoriais, até o espaço do "outro", situado na "beira da maré”, apreendido por alguns moradores de Casa Forte como um lugar de "insegurança", da "marginalidade", endereço das "palafitas", dos "pobres e favelados". 9 Embora não excludentes na totalidade, as realidades sociais separadas pelo Capibaribe, intensificam mais e mais distanciamentos, não obstante o trânsito constante de moradores das comunidades pelo bairro em questão, seja por motivos de trabalho ou lazer. Notadamente percebe-se na paisagem o acúmulo de contenções territoriais, novas "Casas Fortes", redutos da privatização da vida densamente tecnificados em aparatos de segurança. Dentre outros fatores, justifica-se esses enclausuramentos à massiva divulgação do medo e da insegurança pelos meios de informação; à idealização de um modelo de vida propagado pelas incorporadoras imobiliárias calcado na "proteção da família" frente às ditas "ameaças da cidade"; às estratégias comerciais da indústria dos aparatos de segurança; e à história de ocupação elitista da cidade, desde as Casas Grandes dos senhores de engenho, aos sobrados patriarcais e as ricas residências em arrabaldes à beira do Capibaribe.

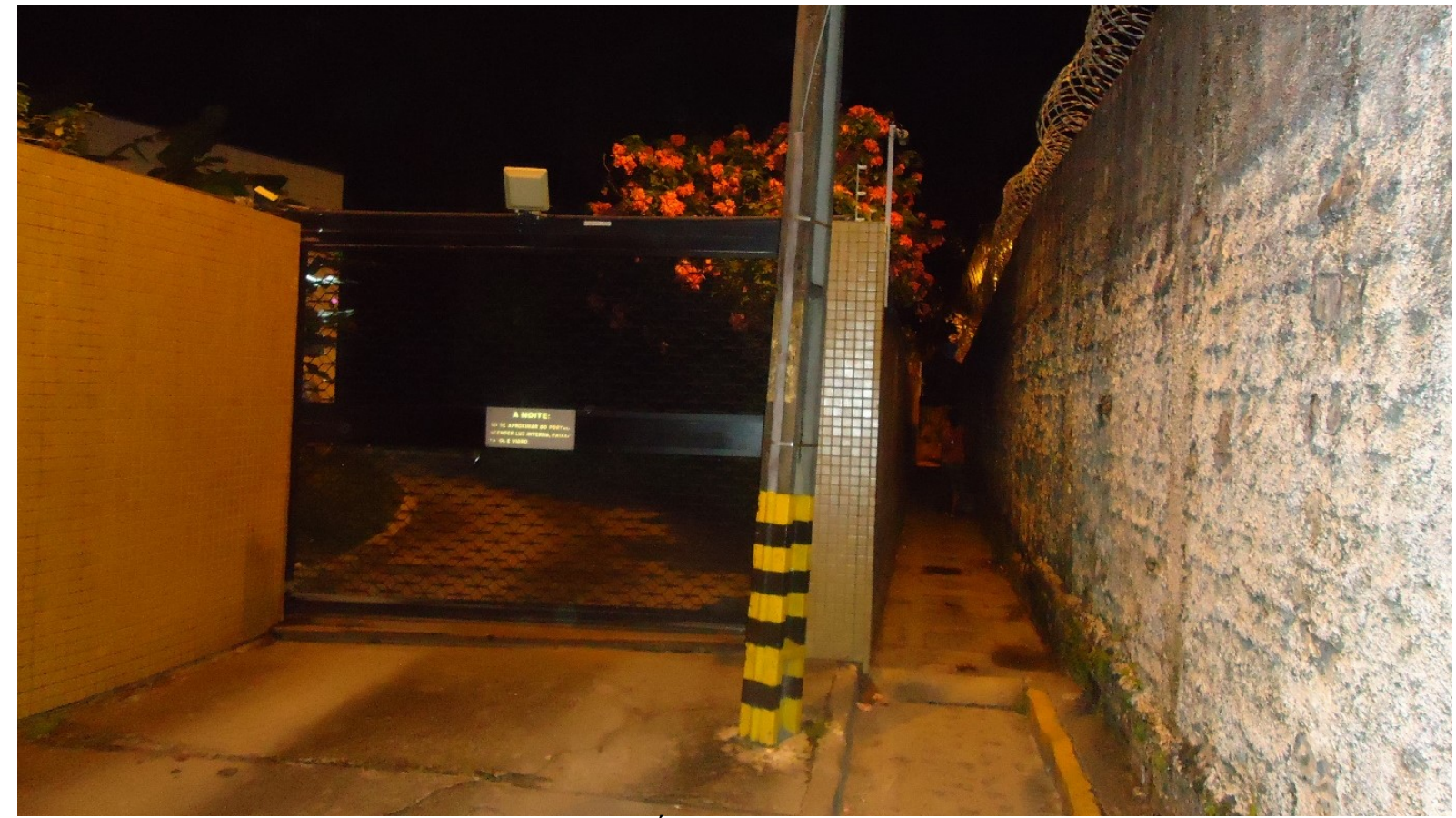

Figura 03: Beco da B, extensão da Rua Edson Álvares, em Casa Forte. Trata-se de uma topofobia do bairro situada nas adjacências da Praça de Casa Forte, marcada pelo conjunto arquitetônico da paróquia do bairro e pelos inúmeros "edifícios-claustros" no seu entorno.

Fonte: Acervo de Lourival Luiz dos Santos Junior, junho de 2017.

\footnotetext{
${ }^{9}$ Conforme depoimentos colhidos em entrevistas realizadas com moradores do bairro, entre os meses de maio e junho de 2017. Ao todo foram entrevistados 08 moradores e trabalhadores de Casa Forte, em meio as ruas, condomínios fechados, vilas, praças, prédios e residências do bairro. 
No espaço imediato do bairro associa-se também os muros e claustros de Casa Forte à própria geografia do lugar, dentro do desarranjo cósmico-humano do Recife. Entre as colinas e o Capibaribe se consolida o bairro. Nos seus limites situam-se comunidades pobres nos morros e nas palafitas, respectivamente. De fora para dentro, o bairro vai se verticalizando até o coração do lugar no entorno da Praça de Casa Forte, deixando nas suas bordas topofobias terrenos baldios, ruas sem saída, becos, mangues à beira do rio, espaços públicos esvaziados e comunidades pobres. Gradativamente o bairro vai se enclausurando em muros e edificações altas, condomínios fechados e ruas privatizadas, espaços permeados por variados sistemas de segurança (guaritas, arames farpados, vidros escuros, câmeras de vigilância, cercas elétricas, "muros-verdes", etc.) até alcançar sua "trama geossimbólica” (BONNEMAISON, 2002) mais expressiva, a praça do bairro, patrimônio projetado pelo paisagista Roberto Burle Marx, ainda em 1937.

Os moradores dos recortes topofóbicos são estigmatizados pelos moradores das casas fortificadas como os causadoras da "desordem", do "crime" e do "mal" na vida do bairro, justificando a necessidade dos claustros-residenciais enquanto territórios de confinamento. ${ }^{10}$ Nestes ambientes, os moradores se sentem mais seguros, "protegidos" pelas redes técnicas de segurança. Mesmo trancafiados nesta individualidade conseguem promover um sentido de coletividade, a partir de certos símbolos de co-pertencimento alusivos à sensação de medo e insegurança circundante, podendo ser vistos como territorialidades. Na ótica de Bonnemaison, a territorialidade consiste numa "[...] expressão de um comportamento vivido: ela engloba, [...] a relação com o território e, a partir dela, a relação com o espaço "estrangeiro". Trata-se de "[...] uma oscilação contínua entre o fixo e o móvel, entre o território "que dá segurança", símbolo de identidade, e o espaço que se abre para a liberdade (Id., Ibid., p. 99-107). Para os moradores mais abastados de Casa Forte, seus “edifícios-claustros" (Figura 06) configuram-se territórios comuns, enquanto a rua e os outros espaços desconhecidos representam ameaças, topofobias do mundo de fora, do mundo real do Recife.

\footnotetext{
${ }^{10}$ Nas entrevistas realizadas entre maio e junho de 2017 com os moradores do entorno da Praça de Casa Forte, observou-se nos discursos o emprego constante destas expressões sempre associadas às geografias topofóbicas do bairro, e às pessoas que ali residem, em especial das comunidades pobres às margens do Capibaribe. 


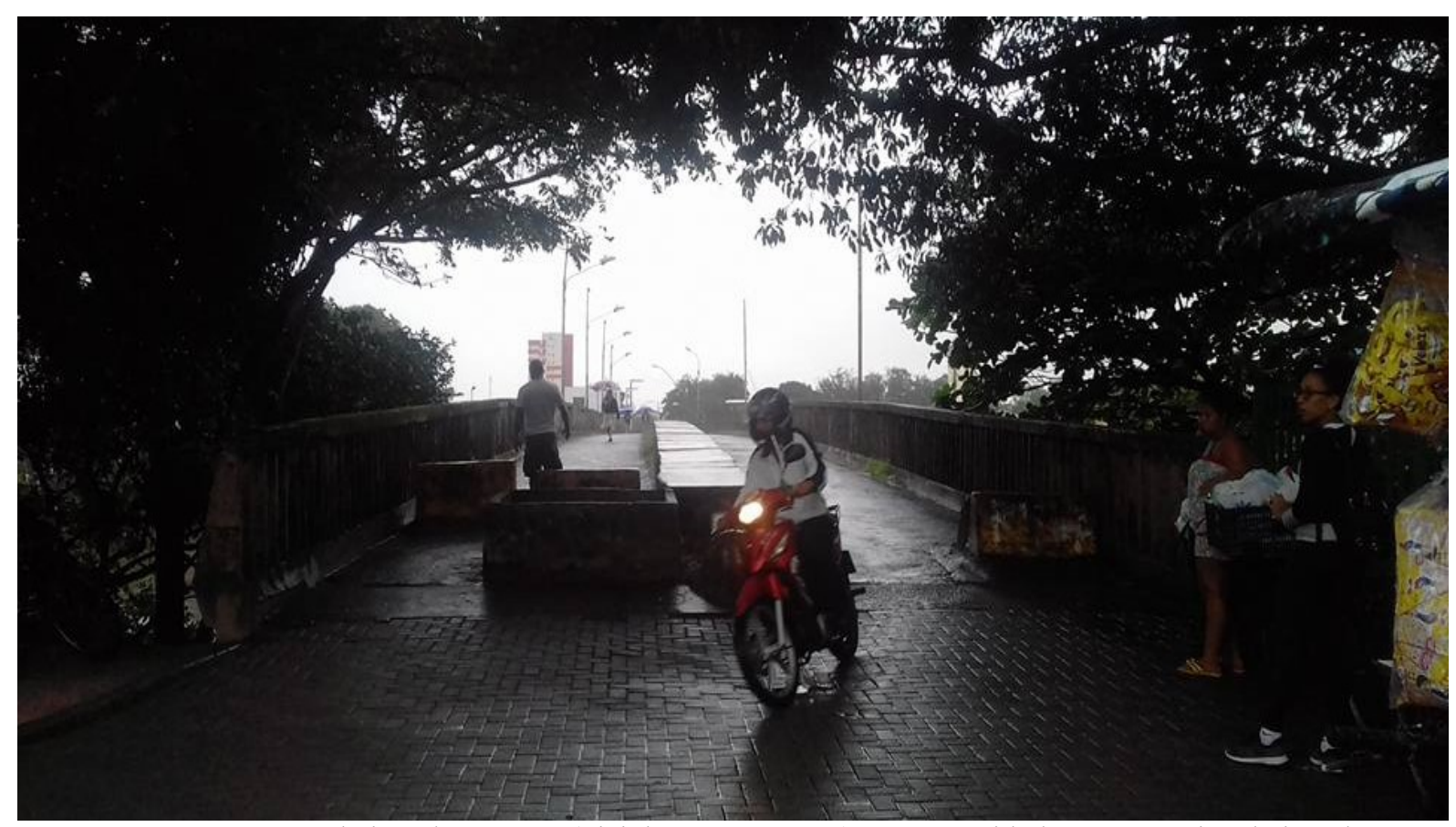

Figura 04: Ponte entre o bairro de Santana (vizinho à Casa Forte) e a comunidade Santa Luzia - bairro da Torre. Observa-se pedestres, ambulantes e um motociclista na margem esquerda do rio Capibaribe, nas imediações do Parque de Santana.

Fonte: Acervo de Bruno Maia Halley, junho de 2017.

O bairrofobia emerge essencialmente na rua, entendida como um lócus do perigo, do inusitado, de um possível pânico, resultado de traumas vivenciados ou relatados por outros na memória compartilhada do lugar. A negação ao público, ao espaço da rua, inverte-se ao desejo do confinamento atrás dos muros. Entre a rua e a casa ergue-se um muro alto, com a rígida delimitação visual entre o público e o privado. A forma hostil expressa na paisagem funciona como uma contenção para a coesão social, produzindo também "muros simbólicos" marcados por isolamentos e ruas esvaziadas de gente. Morador de Casa Forte há 45 anos, Marcelo Costa relatara a mudança no uso das ruas do bairro: “Antes era muito aprazível, tranquilo, os vizinhos ficavam sentados nas calçadas, na rua, conversando... Com o tempo, os mais velhos foram morrendo e o bairro também... A violência aumentou... Já pularam aqui em casa e eu saí correndo atrás dele até Santa Luzia (a comunidade)!”. ${ }^{11}$ Rememorar um passado implica na idealização de um "paraíso perdido", no dizer de Cardoso (2014, p. 33). A retórica de Marcelo talvez fosse a mesma daqueles que viviam o bairro no passado, baseada num "hoje violento" em oposição a um "ontem pacífico". Deste modo, "no tempo presente às pessoas projetariam a imagem de um estado pacífico, idílico, para um tempo pretérito, que é mítico, já que de fato nunca teria existido" (Id., Ibid.).

\footnotetext{
${ }^{11}$ Marcelo Costa, 45 anos, morador de Casa Forte, em entrevista realizada em 25 junho de 2017.
} 


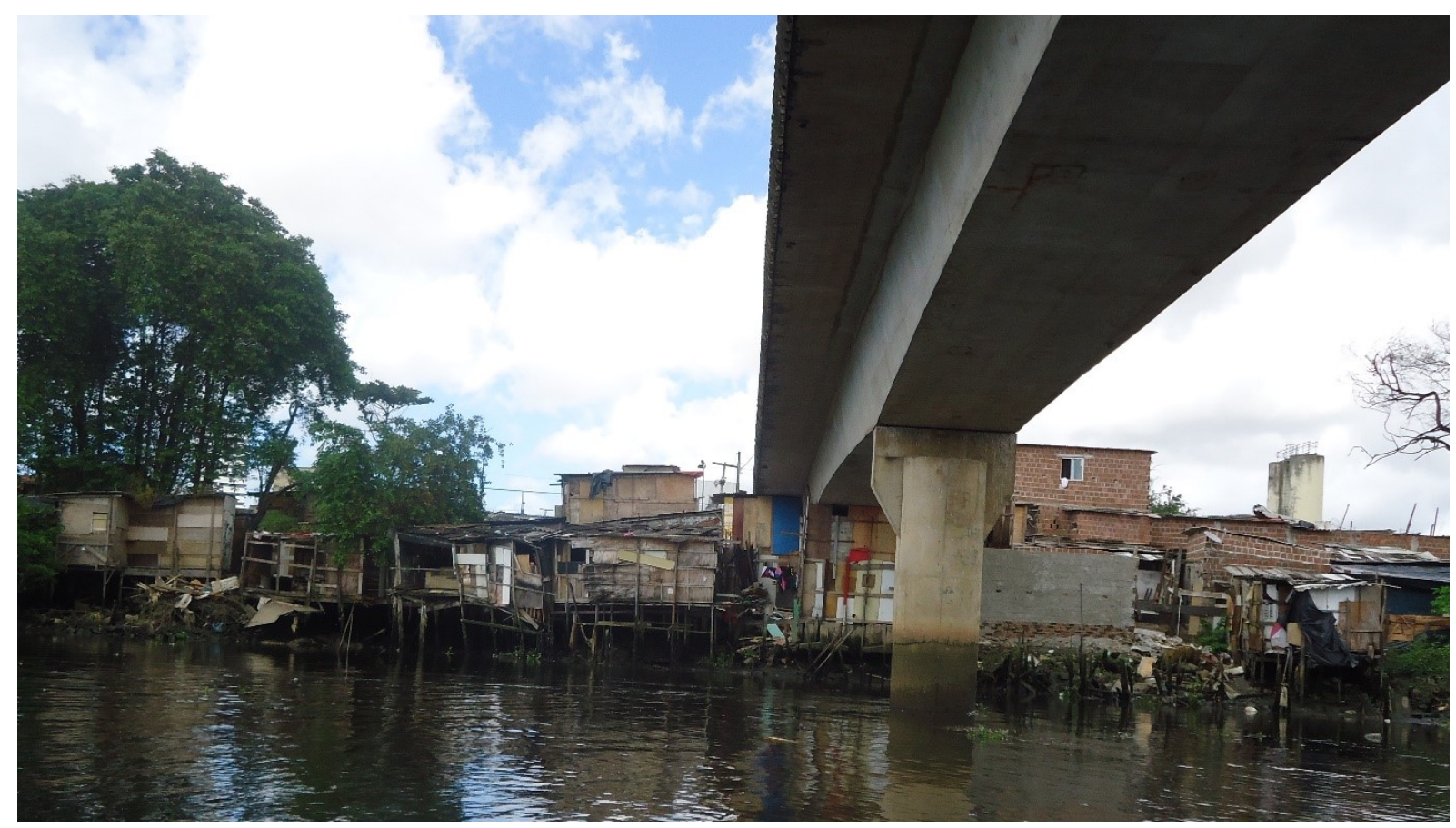

Figura 05: Comunidade Santa Luzia situada no bairro da Torre. Observa-se uma ponte de pedestre sobre o rio Capibaribe, entre as palafitas e os bairros de Santana e Casa Forte, na outra margem do curso d'água. Fonte: Acervo de Lourival Luiz dos Santos Junior, junho de 2017.

Malgrado à complexidade da memória, não há como negar o aumento da violência na ordem do dia, tampouco o menor contato nas ruas de certos bairros, e a consequente perda de uma vida coletiva. O relato do morador de Casa Forte ainda permite pensar as reações engendradas em face à banalização da violência na cidade, resultando nas mais intempestivas resistências entre os citadinos, confundindo em muitas situações, os papeis de agressor e de vítima. Além de querer fazer "justiça com as próprias mãos", Marcelo relatou a intenção de construir um muro ainda mais alto para sua residência, com "três metros de altura". Durante a entrevista referiu-se à sua casa como "Alcatraz” (Figura 07), alusão direta à famosa prisão de segurança máxima norte-americana, construída sobre uma ilha homônima na baía de São Francisco, na Califórnia. Na "prisão inescapável" de Alcatraz, os detentos eram obrigados a cumprir pena. Em bairros como Casa Forte, as "prisões" são voluntárias, forjadas pelos próprios moradores em recusa ao mundo exterior, ao contato público da rua. Nestas situações de confinamento sedimenta-se vários claustros materiais e simbólicos na cidade, com as "vidas emparedadas", lembrando o famoso romance de Carneiro Vilela (2013), "A Emparedada da Rua Nova", ambientado no Recife, cujo próprio nome advém de uma muralha natural de arrecifes areníticos. Parece haver, assim, uma relação indissociável da cidade com 
o muro, não obstante o seu vínculo com as águas, historicamente análogo à Veneza Americana.

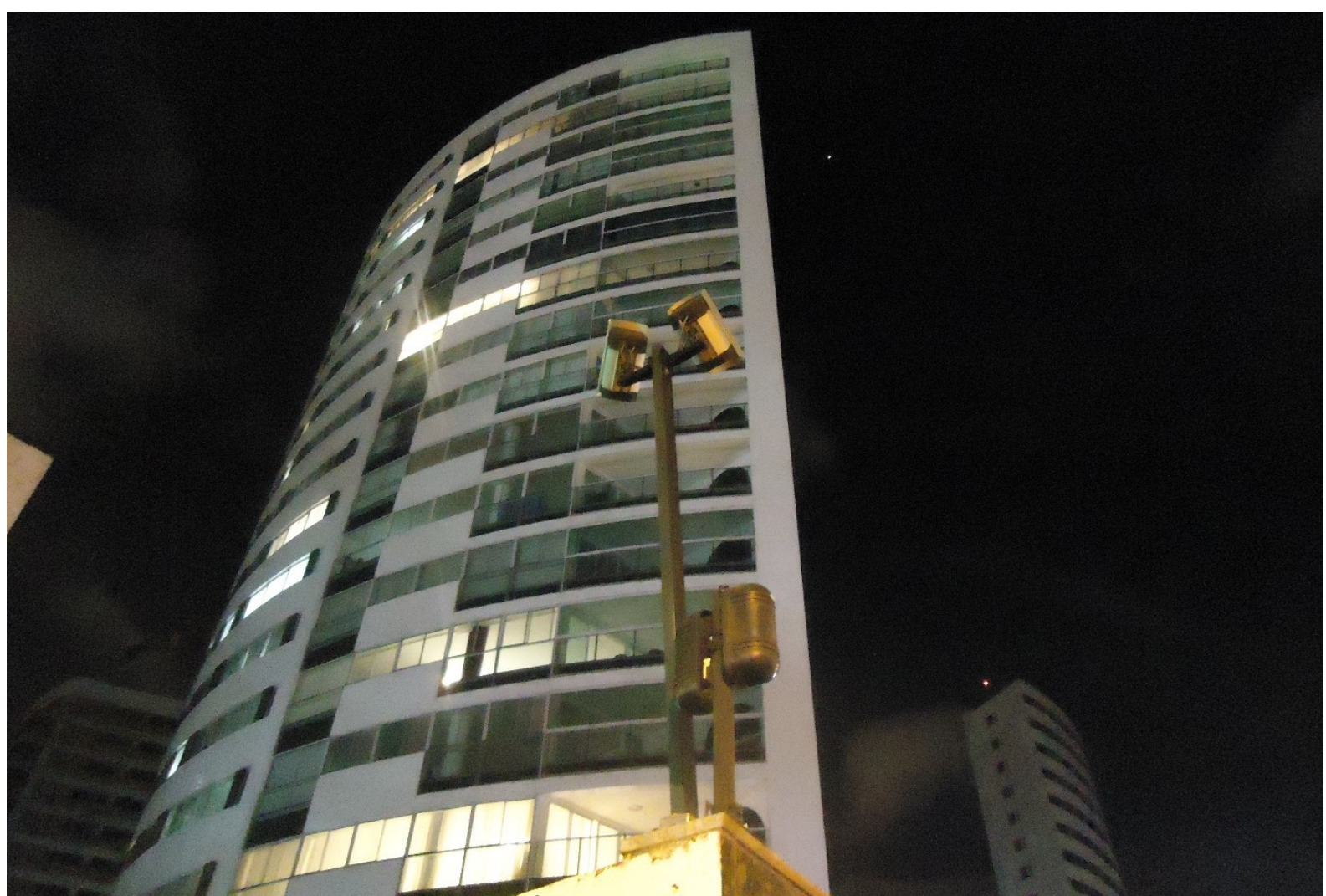

Figura 06: "Edifício-claustro" Engenheiro Élvio Dalla Nora, na Estrada do Encanamento, Casa Forte, e seus aparatos de segurança a vigiar e controlar a vida dos moradores do bairro.

Fonte: Acervo de Bruno Maia Halley, junho de 2017.

\section{NOTAS FINAIS - CONTORNANDO MEDOS E MUROS}

O medo possui a capacidade de transformar a percepção dos indivíduos em relação à cidade, engendrando em muitos casos, um imaginário de desilusão, de arruinamento de uma vida social amistosa, dentro do espaço onde se habita. Topofobias e toponímias do medo são recriadas incessantemente nas cidades, nos seus bairros, nos seus recantos mais esquecidos... As experiências indesejadas, os traumas vivenciados, acabam por redefinir itinerários, usos e lugares na cidade. Em alguns bairros, o caminhar pelas ruas tornara-se um ato solitário por espaços ermos, corredores murados, regidos por um modelo de vida marcadamente anônimo, frio e impessoal, contraposto à noção de bairro como lugar de vivência coletiva, lócus comum de vizinhos, parentes e compadres (HALLEY, 2014). 


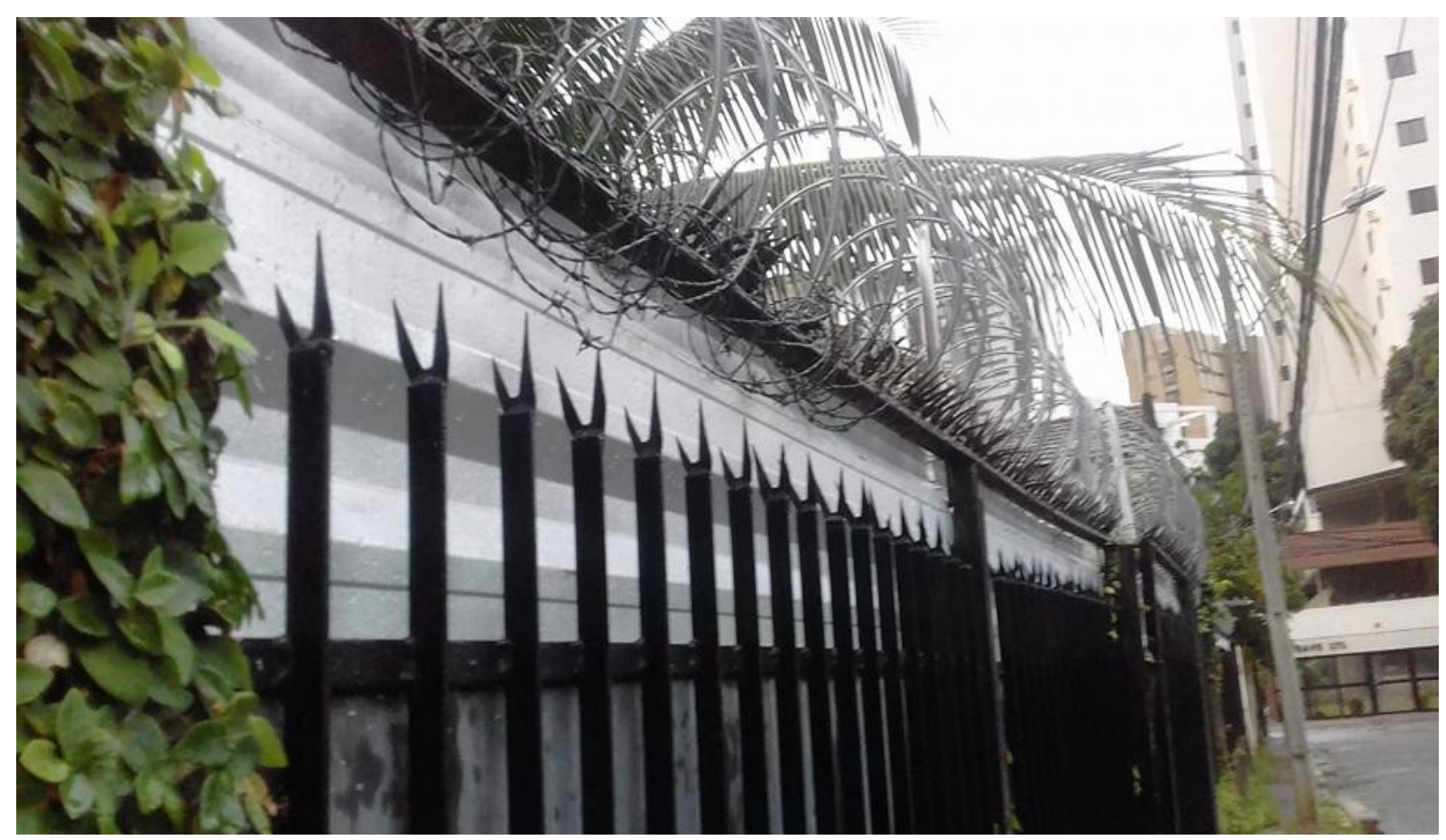

Figura 07: "Alcatraz" - "residência-claustro" de Marcelo Costa, morador do bairro de Casa Forte. A casa na Rua Ambrozina Carneiro recorda um presídio de segurança máxima com muro alto, grade, serpentina farpada e um tapume "protegendo" e bloqueando a visibilidade do imóvel.

Fonte: Acervo de Lourival Luiz dos Santos Junior, junho de 2017.

A realidade atual das cidades revela-se cada vez mais repleta de claustros simbólicos e materiais, negações aos espaços de cidadania. Embora as trincheiras estejam emergindo num ritmo acelerado, nem tudo fora capturado pela embriaguez em curso. Aqui e acolá explodem movimentos a favor do uso público dos espaços, quando não nota-se na paisagem resistências em pequenos atos corriqueiros, aparentemente sem sentidos, que cadenciam o ritmo e a alma do lugar, permitindo o envolvimento mútuo das pessoas. A sobrevivência do bairro como algo maior à um referencial vazio, malgrado o medo e a insegurança exacerbada, se deve, em grande parte, à essa sociabilidade, e também à uma simpatia, envolvida em laços de afeição pelo lugar de vivência, chamada por Souza (1988) de "bairrofilia".

Embora Casa Forte represente um sentimento oposto, uma "bairrofobia", ainda há em alguns fragmentos do seu tecido aspectos comuns de uma vida coletiva, sobretudo em se tratando das comunidades pobres circundantes. Trata-se da intimidade social nas ruas estreitas, calçadas ou entre muros baixos de casas geminadas; o jogo de bola nos campinhos improvisados e praças; além dos encontros diários nas padarias e mercearias. Também entre os moradores dos "edifícios-claustros" há algum tipo de sociabilidade na Praça de Casa Forte, e nos bares, cafés e livrarias do entorno, o que possibilita pensar meios para contornar os \begin{tabular}{lcc} 
medos e muros do bairro, embora os estigmas construídos sobre os espaços dos "outros" \\
\hline Santos Junior, Halley 2018
\end{tabular} 
sejam mais complexos de serem desfeitos na "fobópole" (SOUZA, 2008) recifense.

\section{Referências}

ARENDT, H. A condição humana. 10 ed. Rio de Janeiro: Forense Universitária, 2011.

BONNEMAISON, J. "Viagem em torno do território". In: CORREA, R. L.; ROSENDAHL, Z. (Orgs.). Geografia cultural: um século. Rio de Janeiro: EDUERJ, p. 83-131, 2002.

CALDEIRA, T. P. do R. Cidade de muros: crime, segregação e cidadania em São Paulo. São Paulo: Edusp, 2011.

CARDOSO, B. de V. Todos os olhos: videovigilâncias, voyeurismo e (re)produção imagética. Rio de Janeiro: Ed. UFRJ, 2014.

CARLOS, A. F. A. O lugar no/do mundo. São Paulo: Hucitec, 1996.

CLAVAL, P. Terra dos homens: a geografia. São Paulo: Contexto, 2010.

COUTO, M. "Murar o medo". In: Conferência de Estoril, 4, 5 e 6 de maio, Portugal, 2011. Disponível em: www.estorilconferences.org/pt Acesso: 15 de maio de 2017.

CRUZ, L. M. da. Morfologias urbanas do medo: a materialização da (in) segurança em bairros nobres do Recife. 2010. Dissertação (Mestrado em Geografia), Centro de Filosofia e Ciências Humanas, Universidade Federal de Pernambuco, Recife.

Relações entre espaço, crime e percepção da violência: um estudo de caso em bairros do Recife. 2015. Tese (Doutorado em Geografia), Centro de Filosofia e Ciências Humanas, Universidade Federal de Pernambuco, Recife.

GONÇALVES, C. W. P. "Da geografia às geo-grafias: um mundo em busca de novas territorialidades". In: Clacso, Consejo Latinoamericano de Ciencias Sociales. La Guerra Infinita Hegemonía y terror mundial, 2002.

GRAHAM, S. Cidades sitiadas: o novo urbanismo militar. 1. Ed. São Paulo: Boitempo, 2016.

HAESBAERT, R. Viver no limite - multi/transterritorialidade em tempos de in-segurança e contenção. 1.ed. Rio de Janeiro: Bertrand Brasil, 2014.

HALLEY, B. M. Bairro rural/bairro urbano: uma revisão conceitual. GEOUSP - Espaço e Tempo, São Paulo, v. 18, n. 3, p. 577-593, 2014.

. Arruando pelo beco: um nome do passado evocado no afeto e no desamor da gente da cidade. Revista de Geografia, PPGEO (UFJF), v. 2, nº 1, 2012.

SÁ, A. J. de. "Os territórios da "civilidade" e da violência em Pernambuco-BR: o caso dos estados de exceção e de morte em espaços da cidade de Recife”. In: ; FARIAS, P. S. 
C. (Orgs.). Ética, identidade e território. Recife: CCS Gráfica e Editora, 2012.

. "O ressurgimento dos espaços de cidadania, civilidade e liberdade no Brasil: uma via com saídas nas encruzilhadas dos labirintos das Geografias da Violência e Medo". In: . (Org.). Nas geografias da violência... O renascer dos espaços de civilidade.

Recife: Editora Universitária da UFPE, 2009.

SÁ, A. J. de; CRUZ, L. M. da. (Orgs). "Medo urbano" e suas novas formas geográficas. Recife: Ed. Universitária da UFPE, 2011.

SOUZA, M. L. de. Fobópole: o medo generalizado e a militarização da questão urbana. Rio de Janeiro: Bertrand Brasil. 2008.

. O que pode o ativismo de bairro? Reflexão sobre as limitações e potencialidades do ativismo de bairro à luz de um pensamento autonomista. 1988. Dissertação (Mestrado em Geografia) - Centro de Ciências Matemáticas e da Natureza, Universidade Federal do Rio de Janeiro, Rio de Janeiro.

SPOSITO, M. E.; EDA M. G. Espaços fechados e cidades: insegurança urbana e fragmentação socioespacial. 1ª Ed. São Paulo: Editora UNESP, 2013.

TUAN, Y. Paisagens do medo. São Paulo: Editora UNESP, 2005.

VILELA, C. A emparedada da Rua Nova. Recife: CEPE editora, 2013. 